\author{
Military Technical College \\ Cairo, Egypt
}

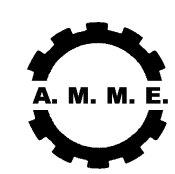

$12^{\text {th }}$ International Conference

on Applied Mechanics and

Mechanical Engineering (AMME)

\title{
THE QUALITY OF AL-SI CASTING OF L SECTION USING WILLIAM'S CORE AND ELLIPTICAL AND SPHERICAL RISERS
}

\author{
IBRAHIM*,M., ISKANDER ${ }^{* *}, B . A$. and MOHIE, ${ }^{* * *}$ M.
}

\begin{abstract}
The transformation from the liquid to solid state is accompanied by the volumetric shrinkage that occurs during solidification.

Risers are used in the production of castings for the purpose of providing molten metal for the solidifying and shrinking casting. Riser design in sand castings requires, at a minimum, that the riser solidify after the casting. The most important aluminum foundry alloys are based on the Al-Si system, especially the hypo-eutectic alloys with compositions ranging from 7 to $11 \mathrm{wt}$. \% silicon. In the present work blind riser of elliptical and spherical shapes were used in the casting of "L"section of two different sizes.

The ratio between the casting modulus to the riser modulus was studied.

William's core was also used to study the effect of applying pressure on the quality of Al -Si alloy .The results showed that the position of the riser and the pouring gate influence significantly the soundness of the Al- Si castings.

The casting of "L" section with large size showed sound casting when elliptical riser is used, and when the pouring gate was placed beside the riser and relative modulus was 1.5.Also the proportion of feed metal available from the feeder which meets the modulus $\%$ C was 9.7.

Sound casting for "L" section of small size was observed when the spherical riser with relative modulus 1.0 was used and the \% C was 8.4 . Using the spherical riser in this case leads to save the material by $20 \%$.
\end{abstract}

\section{KEYWORDS}

Shrinkage cavity, elliptical riser, spherical riser, pouring gate, casting modulus

* Prof .M. Ibrahim, Mechanical department, Faculty of Engineering, Banha University

** Assoc. Prof, B.A.Iskander, Academy of Specialized Studies - Technology department Nasr City, Cairo.

*** Eng . M. K.Mohie . Academy of Specialized Studies - Technology department Nasr City, Cairo. 


\section{INTRODUCTION}

Aluminum is a very important metal because of its low density and excellent mechanical properties, properties which stem largely from its face centered cubic crystal structure. It is alloyed with elements like $\mathrm{Mg}, \mathrm{Si}, \mathrm{Cu}, \mathrm{Mn}, \mathrm{Fe}$, etc. to produce a variety of wrought products from beverage cans to aircraft structural parts, to cast products like engine blocks and steering knuckles for automobiles [1]. The Al-Si alloy is a well-known casting alloy with high wear resistance, low thermal-expansion coefficient, good corrosion resistance, and improved mechanical properties at a wide range of temperatures. These properties led to the application of Al-Si alloys in the automotive industry, especially for cylinder blocks, cylinder heads, pistons, and valve lifters. They are extensively used in tribological ends, but their poor resistance to seizure makes them vulnerable under poor lubricating conditions [2, 3]. Addition of ceramic particulate to these alloys increases stiffness, high-temperature strength, and wear resistance at ambient temperature while the use of graphite (or carbonaceous precursors) and mica lend it to reduced friction applications such as bearings, solid lubricants, and braking components.[4]

The most important aluminum casting alloys, on a tonnage basis, are those which depend upon the eutectic reaction to improve cast ability, to lower energy input and pouring temperature, and to produce desirable cast microstructures. These aluminum alloys contain primarily $\mathrm{Si}, \mathrm{Mg}$, and $\mathrm{Cu}$.

Hypereutectic aluminum-silicon alloys (alloys with greater than $12 \%$ silicon) have outstanding wear resistance, a lower thermal expansion coefficient, and very good casting characteristics. Such alloys have traditionally received only limited attention and use because the presence of the extremely hard primary silicon phase reduces tool life during machining, so the casting process for these alloys is the simplest, most direct route to a near net shape product, and often the least expensive.[5]

Almost $17 \%$ scrap arises directly from shrinkage defects in an audit of aluminum casting machinery rejects. In addition to this, porosity associated with oxide inclusions accounts for another $22 \%$. Entrapped air accounts for $50 \%$ of such rejects; thus, the bulk of rejects in this audit involve some form of porosity. The pressurization technique investigated should be capable of suppressing each of these forms of porosity [6]

The most important aluminum foundry alloys are based on the Al-Si system, especially the hypo-eutectic alloys with compositions ranging from 7 to 11 wt. \% silicon. Solidification of these alloys is characterized by four events: (1) a short nucleation event, followed by (2) growth of the dendrites until they impinge on one another, (3) growth and coarsening of the dendrite arms, and finally (4) eutectic precipitation. Silicon hypoeutectic casting alloys. Understanding the mechanism of eutectic formation is essential to analyze the resistance to melt flow. Melt flow influences feeding efficiency, which, in turn influences shrinkage, porosity formation, and segregation. Producing a "good" casting for the intended application requires the following:

1. Create a gating system (pouring basin, sprue, and runner) to bring molten metal into the mold cavity free from entrapped slag, sand or gases.

2. Provide a riser which feeds liquid metal into the casting cavity as the liquid is cooling and solidifying (all liquid metals will shrink as they cool and most liquid metals will shrink 
as they solidify). The riser may have to provide up to $5-7 \%$ by volume for the casting as it solidifies.

3. Control heat flow out of the casting so that the last liquid to solidify is in the riser.

4. Control the rate of heat flow so as to control the nature of the solidified product [7].

Risers are used in the production of castings for the purpose of providing molten metal for the solidifying and shrinking casting. Riser design in sand castings requires, at a minimum, that the riser solidify after the casting.

Internal macroshrinkage results when the riser does not adequately feed the casting, but the casting has established a solid shell against the mold wall which is able to resist deformation due to the stresses generated by the pressure difference. The result is the retention of large macro shrinkage

inside the casting.

External Macroshrinkage results when the solid shell is not strong enough to resist the shear stresses generated by the pressure difference. The result is the surface collapses into the vacuum created by the density differences resulting from solidification. $[8,9]$ The atmospheric pressure is an important in the risers of castings. Properly applied atmospheric pressure can substantially improved riser effectiveness. Blind risers are totally enclosed in sand and to maintain atmospheric pressure within the molten metal in the blind risers, a core known as pencil core or William's core is used.[ 10 ] The core acts as a hot spot and atmospheric pressure acts through the sand core and pushes liquid metal from risering up to the casting. Round risers have lower ratio of surface area to volume than square or rectangular risers. [11].

In the present study the spherical and elliptical risers were used in the casting of $\mathrm{Al}-\mathrm{Si}$ alloy of $L$ section shape using William's core. The effect of the riser position and the pouring gate to the casting was also studied in order to obtain sound casting.

\section{Experimental work}

The Aluminum - silicon alloy was received from "The Aluminum Company of Egypt" in the form of slabs. The chemical composition is as follows: $\mathrm{Al}-10.78 \% \mathrm{Si}-0.18 \% \mathrm{Mg}-$ $0.11 \% \mathrm{Fe}$

The sand mold mixture was used with the following constituents:

Bantonite $=10 \%$, Moisture $=5 \%$, for spherical riser water glass (sodium silicate) was added by $4 \%$ and hardened by $\mathrm{CO}_{2}$ gas [12]

In the present work a spherical and elliptical risers were used in order to study the effect of the riser shape, the position and the size on the formation of shrinkage cavity. The dimensions of the "L"section with large and small size are illustrated in Fig (1 and 2) consequently.

The diameter of the riser of spherical type was $98 \mathrm{~mm}$ as shown in Fig (3) was used for the " $\mathrm{L}$ " section with large size, while the diameter of spherical riser used with small " $L$ " was reduced to $86 \mathrm{~mm}$. 

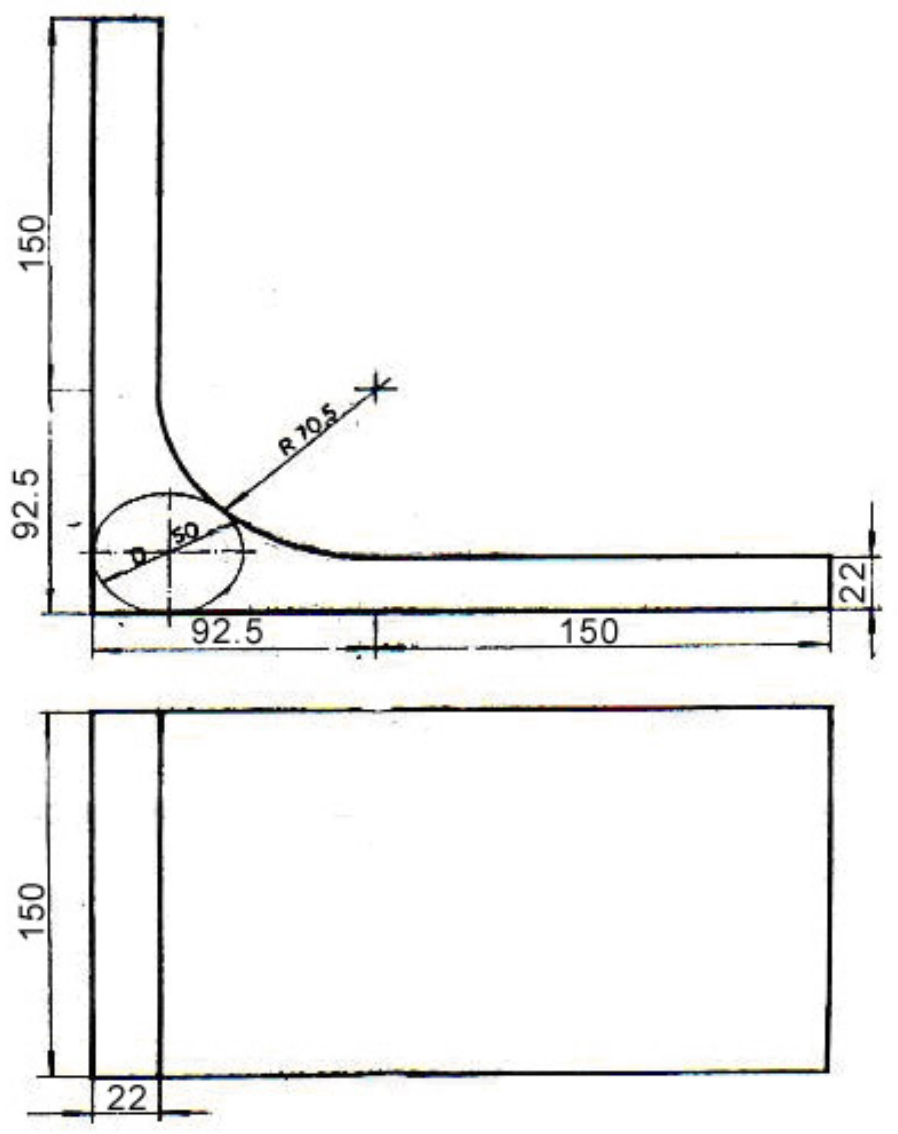

Fig. 1 The dimensions of large size of "L" section $\left(L_{L}\right)$
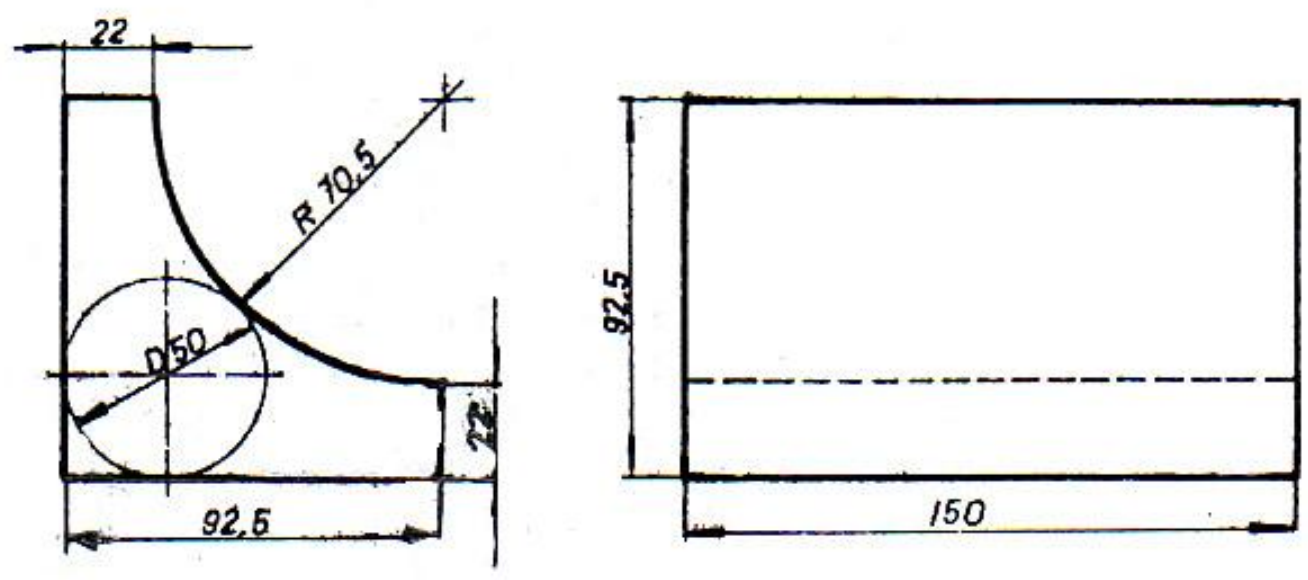

Fig .2 The dimensions of small size of " $L$ "section $\left(L_{s}\right)$ 

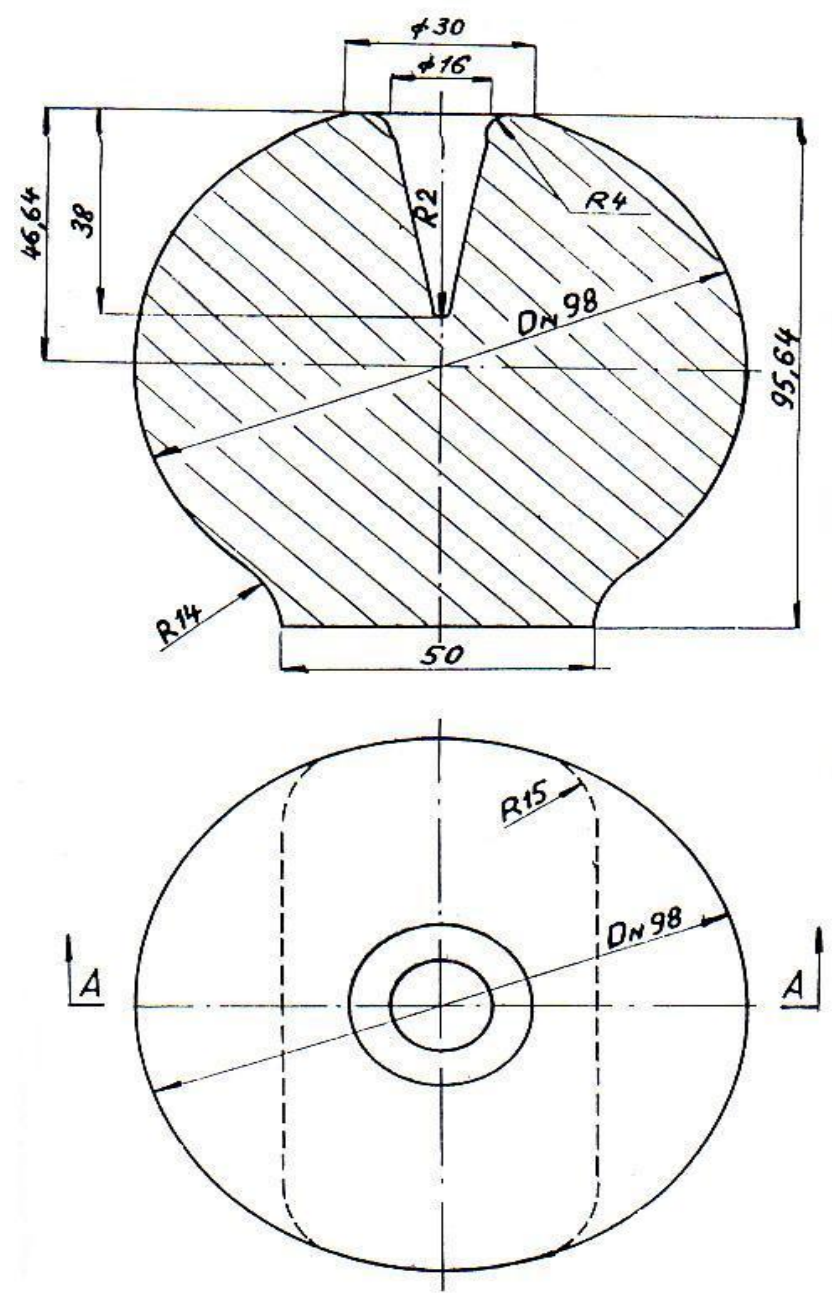

Fig .3 The dimensions of the spherical Riser used with large" $L$ " section $\left(L_{L}\right)$

Fig (4) illustrates the dimensions of elliptical riser used for the $L$ section of large size. The diameter of the elliptical riser used for $L$ section of small size was $78 \mathrm{~mm}$, the height was $109 \mathrm{~mm}$ and the width was $98 \mathrm{~mm}$. William's core was used to increase the pressure inside the riser as shown in Fig (5). A steel bar was used to apply the air pressure on the liquid metal. 

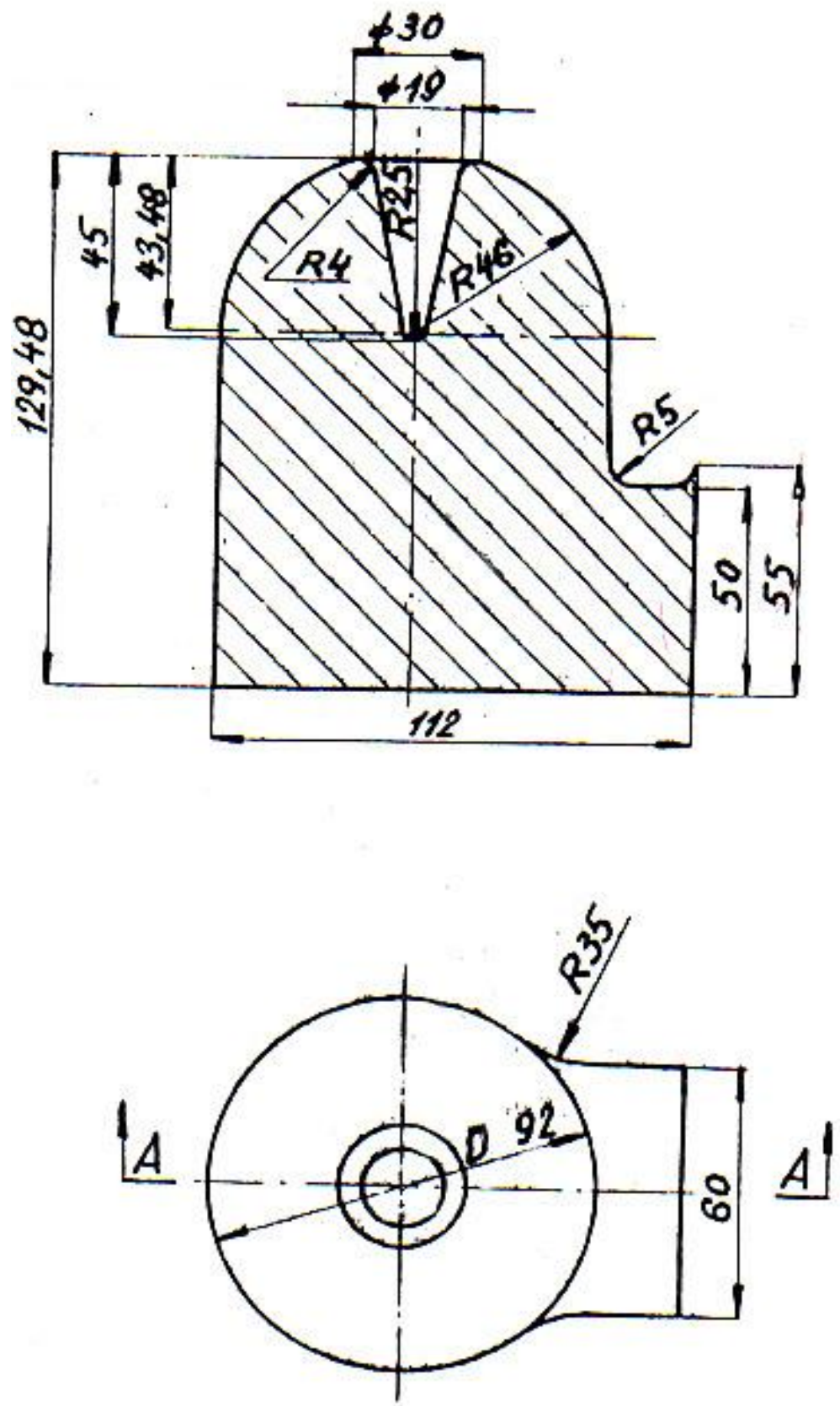

Fig .4) The dimensions of the elliptical riser used for large "L" section 

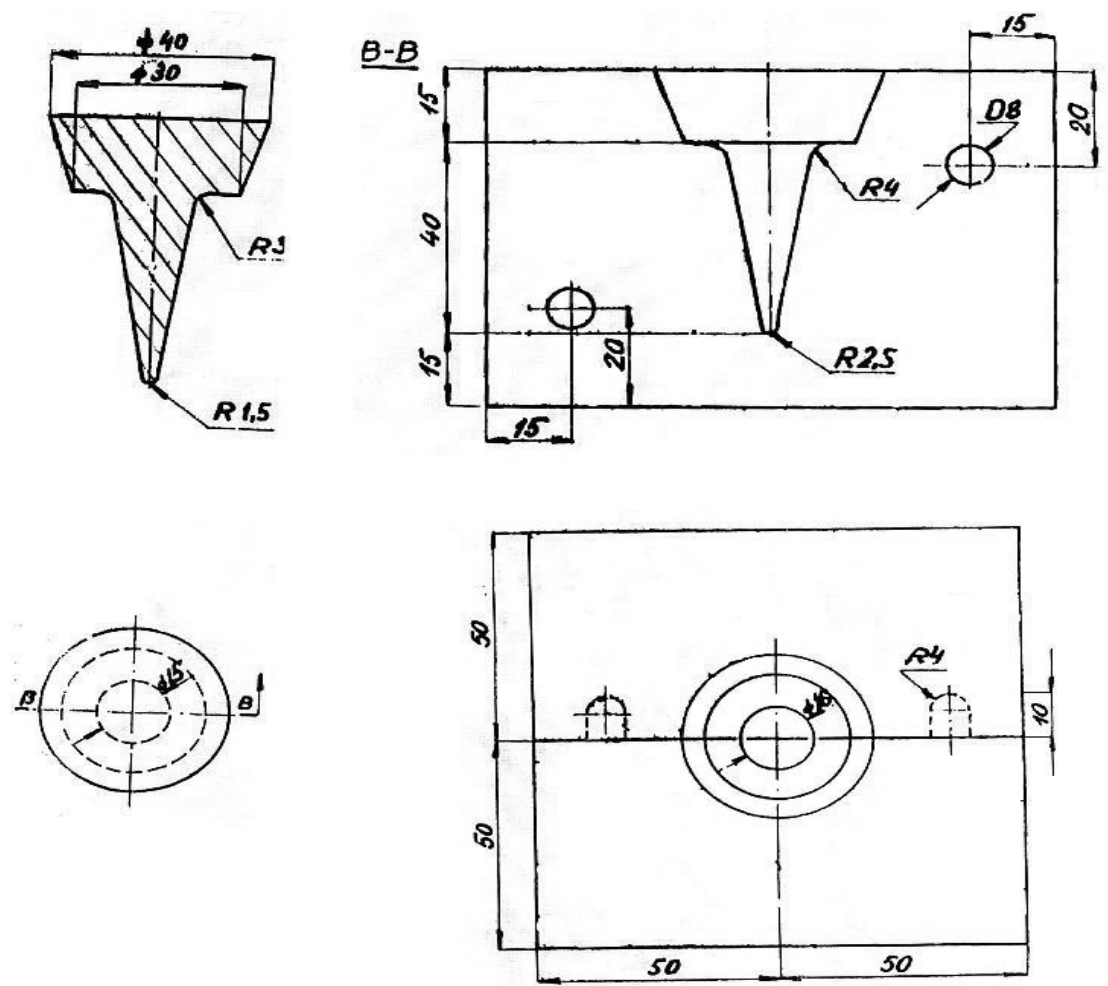

Fig .5 The dimensions of William's core and the pattern

\section{Results and discussion}

The hot spot of the $L$ section for the two sizes under investigation was $50 \mathrm{~mm}$ diameter. The riser's neck was design to be $50 \mathrm{~mm}$ as shown in Fig( 3 and 4 ) blind elliptical and spherical riser were used.

The modules of the two types of riders were calculated and also the modules of the" L" Shape with the two sizes illustrated in Fig ( 1 and 2). The position of the riser was also studied where it is placed beside the casting and the other experiment when the riser was placed between the casting and the pouring gate.

\section{Section (large size)}

The calculations of the volume of the casting of " $L$ "section of large size was $\left(L_{L}\right)$ section $\left(V_{C}\right)=1.688 \times 10^{6} \mathrm{~mm}^{3}$

The surface area of the $\left(L_{L}\right)$ section $\left(A_{C}\right)=1.635 \times 10{ }^{5} \mathrm{~mm}^{2}$

The modulus of the $\left(L_{L}\right)$ section $\left(M_{C}\right)=V_{C} / A_{C}=10.324 \mathrm{~mm}$

The volume of the blind elliptical riser $V_{R}=7.326 \times 10^{5} \mathrm{~mm}^{3}$ 
The surface area of the blind elliptical riser $A_{R}=4.5655 \times 10^{4} \mathrm{~mm}^{2}$

The modulus of the blind elliptical riser $\left(M_{R}\right) V_{R} / A_{R}=15.7379 m m$

The modulus ratio $M_{R} / M_{C}=1.5$ and the volumetric ratio $V_{R} / V_{C}=0.434$

The volume of the spherical riser $V_{R}=5.14 \times 10^{5} \mathrm{~mm}^{3}$

The surface area of the spherical riser $A_{R}=3.783 \times 10^{4} \mathrm{~mm}^{2}$

The modulus of the spherical riser $M_{R}=V_{R} / A_{R}=16.054 \mathrm{~mm}$

The modulus ratio $M_{R} / M_{C}=1.6$ and the volumetric ratio $V_{R} / V_{C}=0.304$

Table (1) shows the $V_{R} / V_{C}$ ratio for elliptical riser is greater than the $V_{R} / V_{C}$ ratio of the spherical riser. On the other handthe $M R / M_{C}$ for spherical riser is greater than for the elliptical riser.

Table .1 The volume and the modulus ratios for elliptical and the spherical risers

\begin{tabular}{|c|c|c|}
\hline Riser Type & $\mathbf{V}_{\mathbf{R}} / \mathbf{V}_{\mathbf{C}}$ & $\mathbf{M}_{\mathbf{R}} / \mathbf{M}_{\mathbf{C}}$ \\
\hline Elliptical & 0.434 & 1.5 \\
Spherical & 0.304 & 1.3 \\
\hline
\end{tabular}

The Foseco foundryman's handbook showed that feeders, whose dimensions satisfy modulus requirements, do not necessarily always satisfy the total feed metal demand of the casting section .For the purpose of feeder size determination, not only that the feeder solidifies over a longer time than the casting, but also satisfied when the riser geometric modulus $M_{R}$ is greater than the casting geometric modulus [13]. By examining that condition on the riser type and the $\mathrm{L}$ section for Al-Si alloy under investigation it can be observed that $M_{R}$ / $M C$ for the elliptical riser 1.5 while for spherical riser it was 1.3 In order to determine the volume of shrinkage cavity, the riser was cut and the cavity was filled with water. The percentage of the volume of shrinkage cavity to the casting volume was $0.02 \%$ when the elliptical riser was placed between the pouring gate and the casting.

The photography for $L$ section shown in Fig (6) illustrates the presence of the shrinkage cavity when the riser is located between the pouring gate and the casting. On the other hand, when the riser was placed beside the casting, the visual inspection in Fig (7) shows the formation of dark, semi-circular feature casting defect (a pore) caused by gas porosity. 


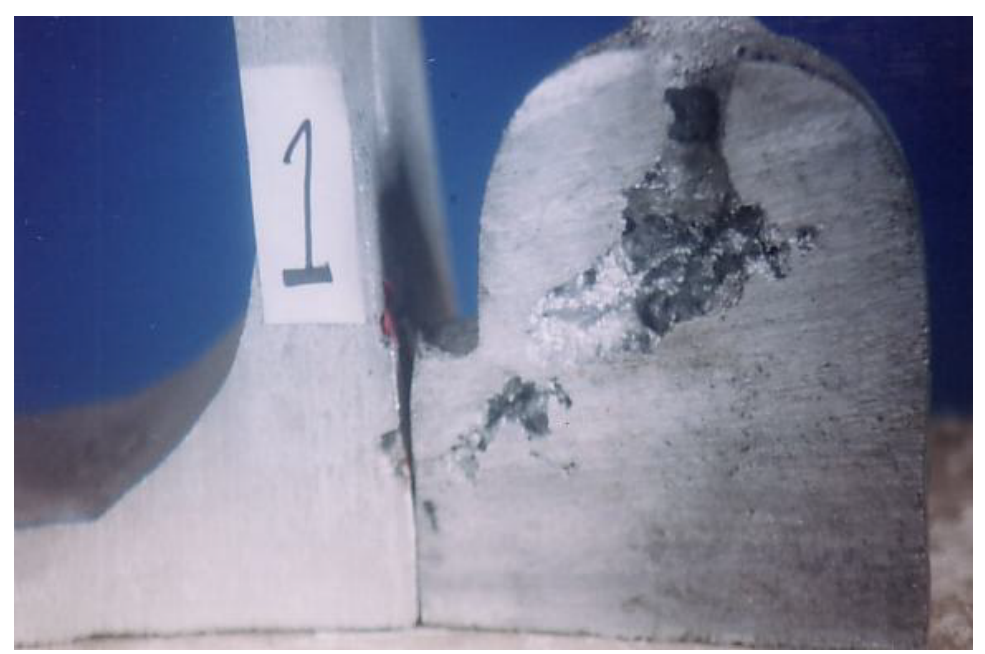

Fig .6 The photography of $L$ (large section) on placing the elliptical riser between the casting and the pouring gate

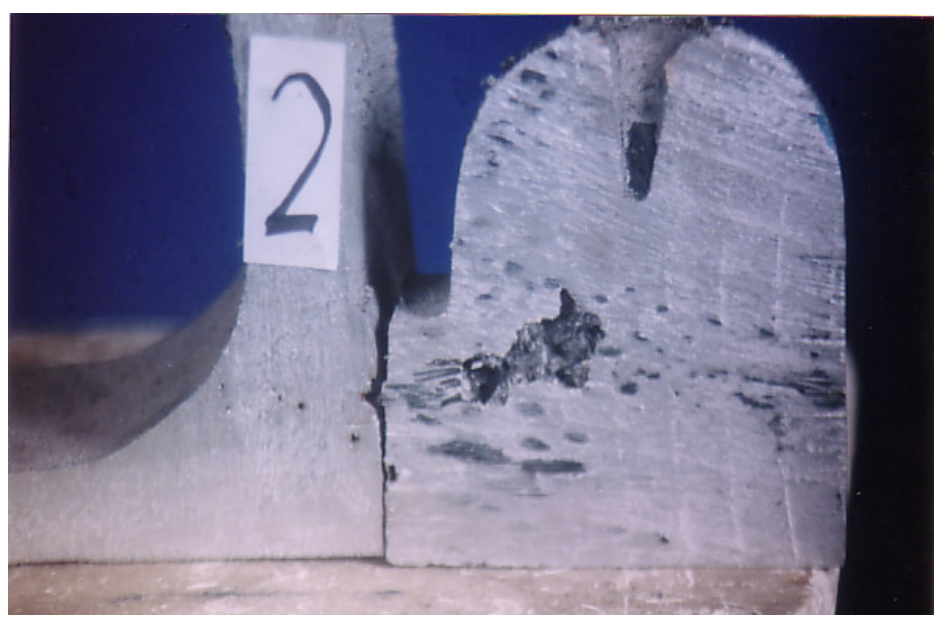

Fig.7 The photography of $L$ (large section) on placing the riser beside the casting

When the spherical riser was used for the casting of $L$ section of large size the shrinkage cavity volume was $0.76 \%$ of the casting volume when the riser was placed between the pouring gate and the riser. The photography shown in Fig (8) illustrates that the shrinkage cavity is shifted from the junction area of the casting. This is attributed to the water glass which was used as a binder for the spherical riser and because it has thermal diffusivity higher than the green sand mould. 


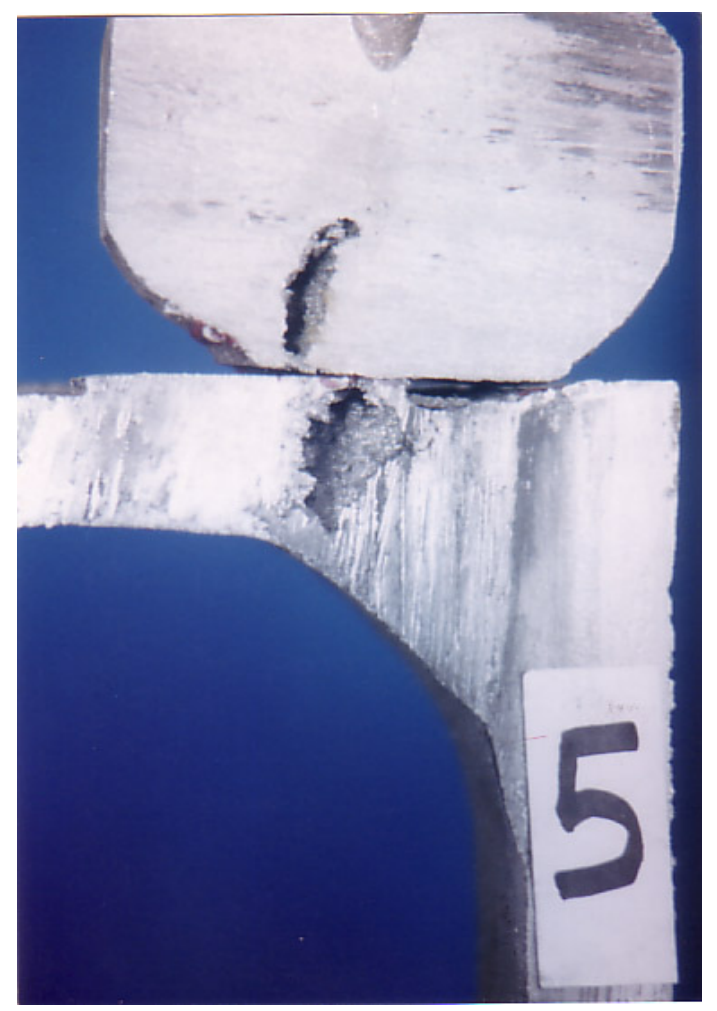

Fig.8 The photography of the large "L" with spherical riser and the riser is placed between the pouring gate and the casting

When the casting was placed between the spherical riser and the pouring gate, the shrinkage cavity was also observed as shown in Fig (9). The calculations of shrinkage cavity volume was $0.38 \%$ of casting volume. This is because of the same reason of using the water glass for binding the sand mixture used with spherical riser. The spherical riser has the advantage that it is smaller surface area leads to slower the rate of cooling. The lower $V_{R} / V_{C} \quad$ ratio of the spherical riser than the elliptical riser this leads to save material by $28 \%$. 


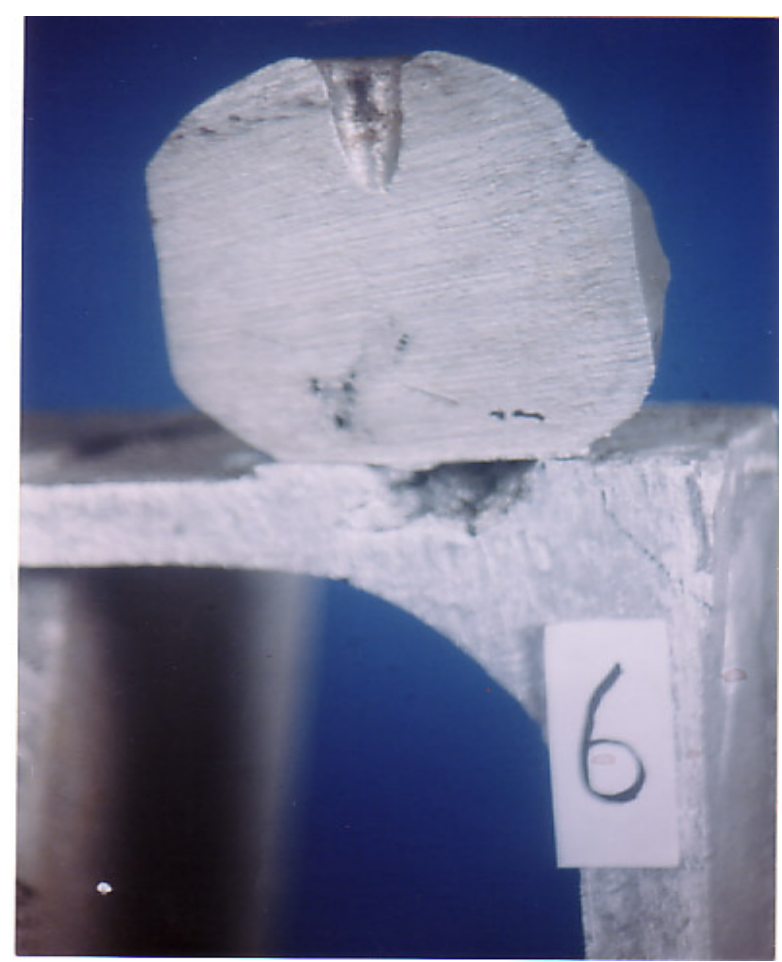

Fig.9 The photography of the large "L" with spherical riser when casting was between the pouring gate and the riser was beside the casting.

Although the feeders satisfy the modulus requirements, shrinkage cavity was observed with spherical riser. So another calculation was checked using the following equation: $W_{C}=\mathrm{C} / 100 * 100 / S * W_{R}[13]$

Where the weight of metal in the feeder under consideration was $W_{R}$, and the total weight of casting which can be fed $\mathrm{W}_{\mathrm{C}}$, and $\mathrm{S} \%$ is the shrinkage of the alloy to be cast which is $4.25 \%$ for $\mathrm{Al}-11 \mathrm{Si}$. C\% is the proportion of feed metal available from the feeder which meets the modulus requirements.

Substitute by the volume in the above equation:

$\mathrm{C} \%=\left(\mathrm{V}_{\mathrm{C}} / \mathrm{V}_{\mathrm{R})}{ }^{*}(\mathrm{~S} / 100)^{*} 100\right.$

The results shown in Fig (10) illustrated that \% C was $14 \%$ for the blind spherical riser which was greater than the elliptical riser which was $9.7 \%$. C\% for the live natural feeder (when the liquid metal flow before it reaches the casting cavity in the mould) is $16 \%$. [13] 


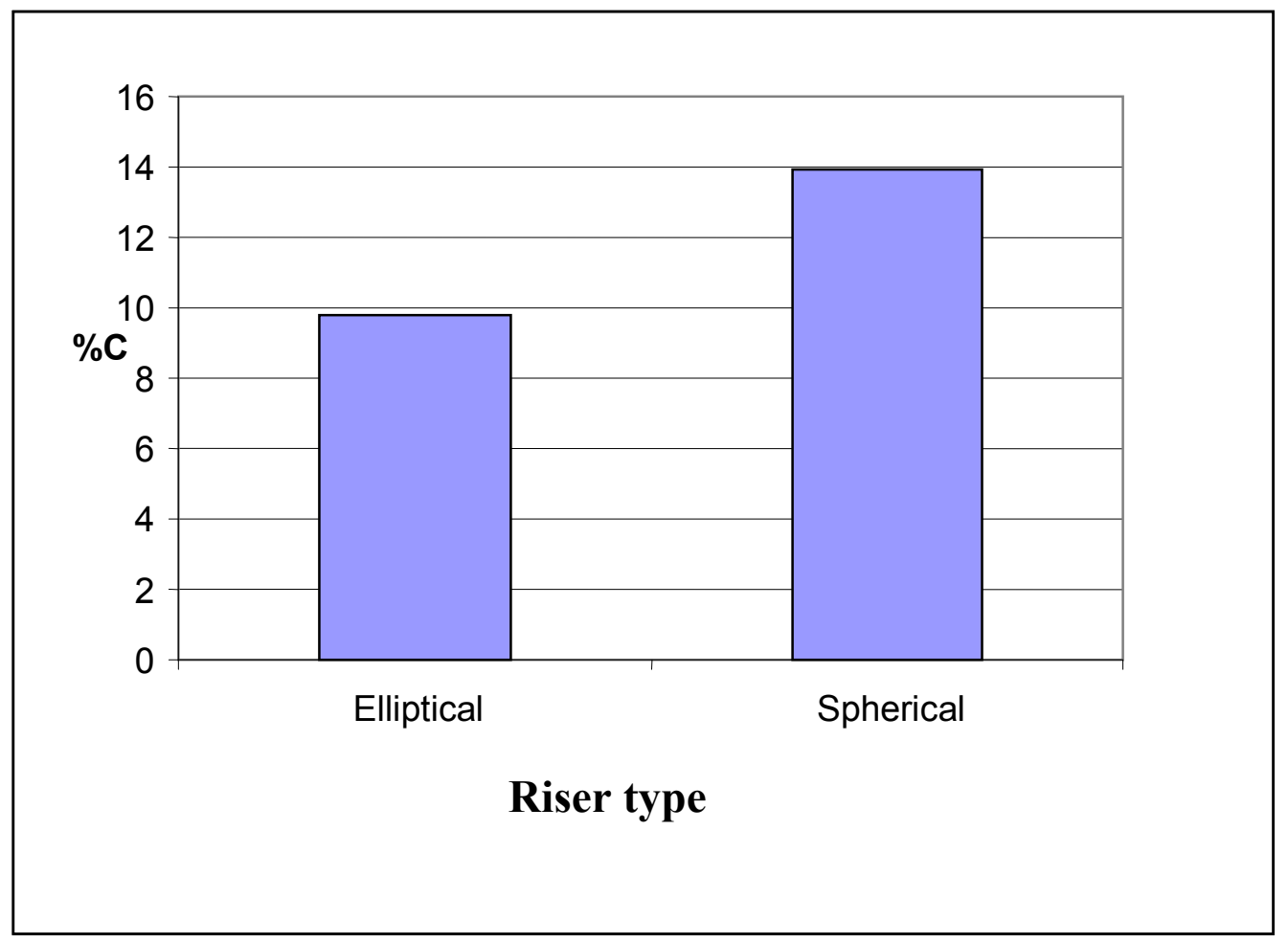

Fig. 10 The $\%$ C for the elliptical and spherical risers

\section{L section with small size}

The elliptical and the spherical riser were also used, and two positions of the riser were studied:

The first: the riser isocated between the casting and the pouring gate.

The second: The pouring gate was located besides the casting.

The calculations for the elliptical riser:

The volume of the $\left(L_{s}\right)$ section $\left(V_{C}\right)=6.979 * 10^{5} \quad \mathrm{~mm}^{3}$

The surface area of the $\left(L_{s}\right)$ section $\left(A_{c}\right)=6.027^{*} 10^{4} \mathrm{~mm}^{2}$

The Modulus of the $\left(L_{S}\right)$ section $\left(M_{C}\right)=\left(V C / A_{C}\right)=11.579 \mathrm{~mm}$

The volume of the blind elliptical riser $\left(V_{R}\right)=5.4^{*} 10^{5} \mathrm{~mm}^{3}$

The surface area of the blind elliptical riser $\left(A_{R}\right)=3.9^{*} 10^{4} \mathrm{~mm}^{2}$

The modulus of the blind elliptical riser $\left(M_{R}\right)=V_{R} / A_{R}=13.889 \mathrm{~mm}$

The modulus ratio $\left(M_{R} / M_{C}\right)=1.2$

The volume ratio $\left(\mathrm{V}_{\mathrm{R}} / \mathrm{V}_{\mathrm{C}}\right)=0.77$

The calculations for the spherical riser

The volume of the spherical riser $\left(V_{R}\right)=3.525^{*} 10^{5} \mathrm{~mm}^{3}$

The surface area of the spherical riser $\left(A_{R}\right)=2.977^{*} 10^{4} \mathrm{~mm}^{2}$

The modulus of the spherical riser $\left(M_{R}\right)=V_{R} / A_{R}=11.841 \mathrm{~mm}$

The ratio $\left(M_{R} / M_{C}\right)=1.02$

The ratio $\left(\mathrm{V}_{\mathrm{R}} / \mathrm{V}_{\mathrm{C}}\right)=0.505$

The surface area and the volume of the spherical riser is less than the elliptical riser. Fig

(11) shows that the ratio of the volume of riser to the volume of casting, and the also the 
riser modulus to the casting modulus ratio is greater in case of elliptical riser than the spherical riser.

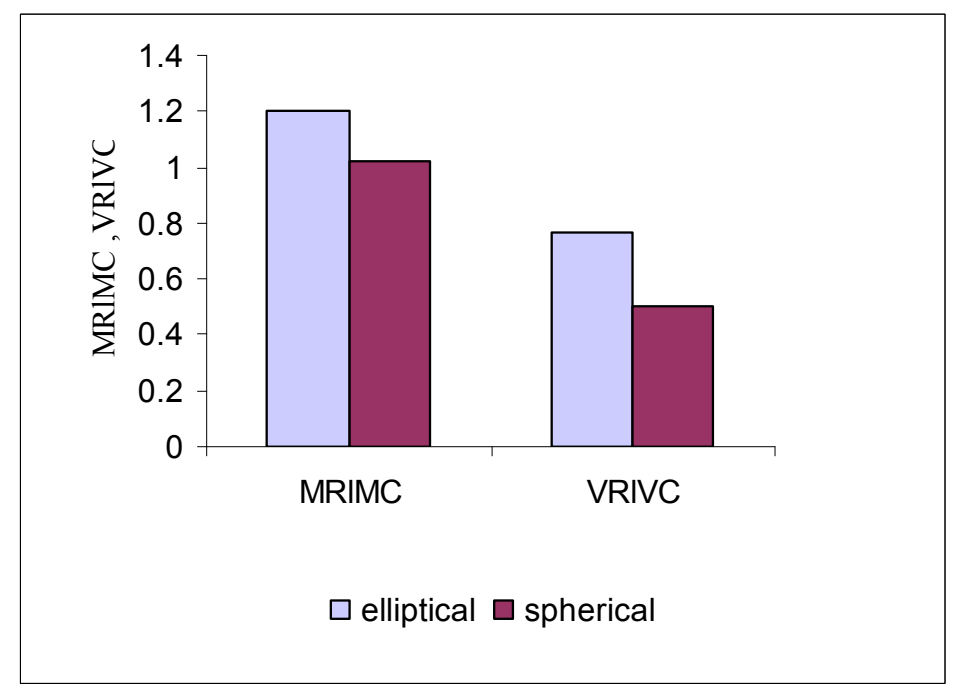

Fig.11 The volume ratio and the modulus ratio of spherical riser and elliptical risersused with $L$ section (small size).

The spherical riser used in casting of the $L$ section of small size save material by $40 \%$. The presence of shrinkage cavity was examined by visual inspection. The castings were cut in horizontal direction and the photography is shown in Fig (12 and 13). It has been observed that when elliptical risers were used in both positions; either when the riser was located besides the casting or between the casting and the pouring gate led to sound casting. 


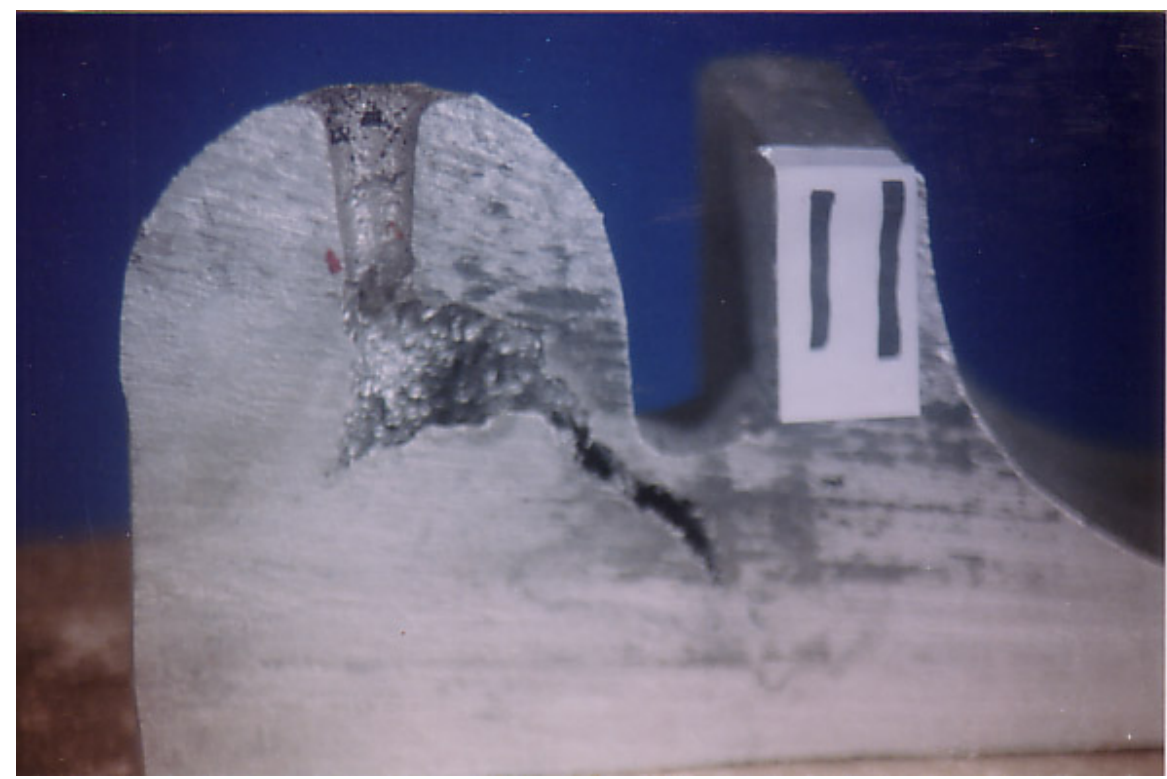

Fig.12 The photography of the small "L" with blind elliptical riser located between the pouring gate and the casting.

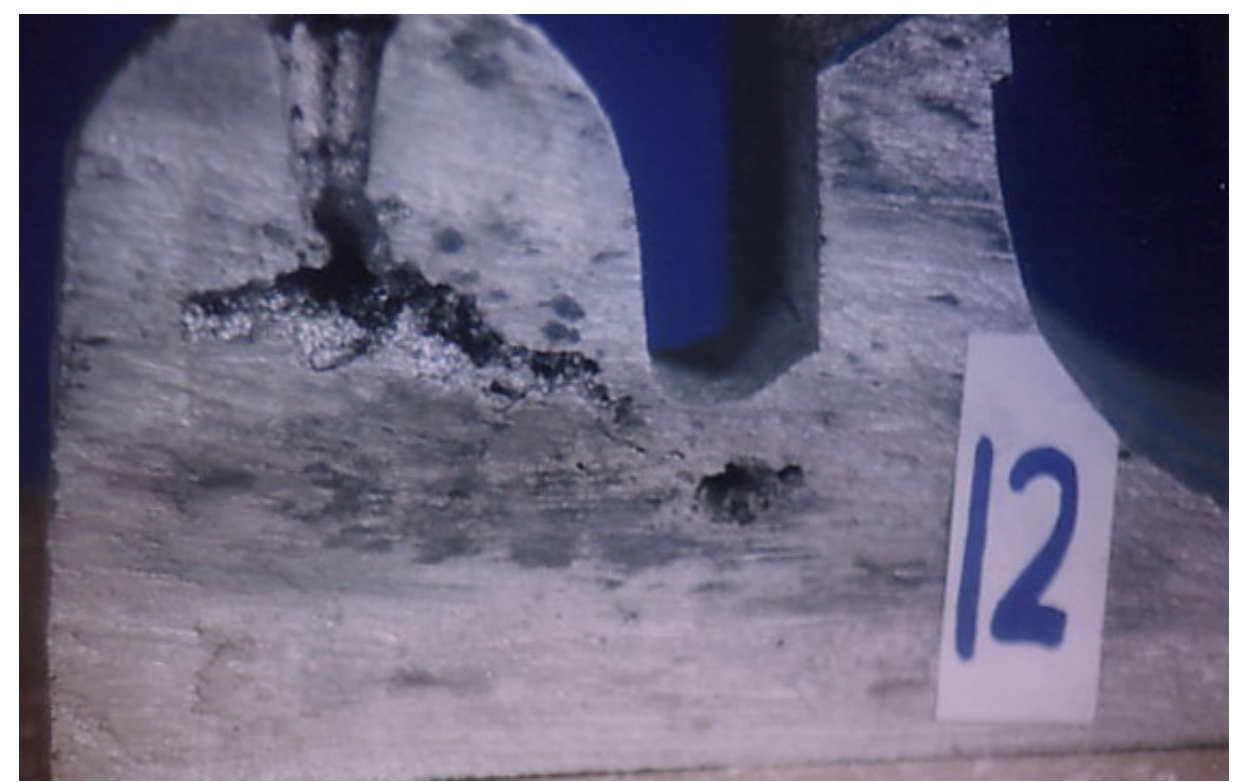

Fig.13 The photography of the small "L" with blind elliptical riser located beside the casting.

On the other hand on using the spherical riser resulted in sound casting when the riser was placed between the casting and the pouring gate while placing the pouring gate besides the casting led to form shrinkage cavity of $0.49 \%$ as shown in Fig( 14 and 15) 


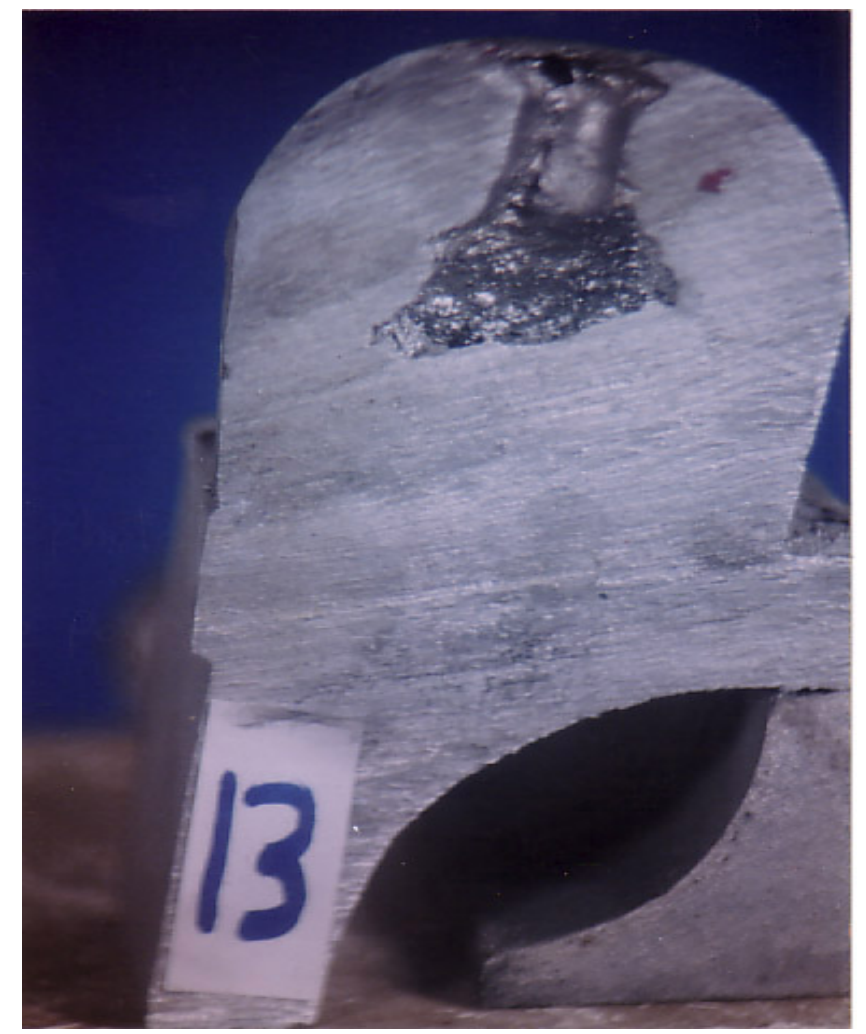

Fig.14 The photography of the small "L" with spherical riser and the tween the pouring gate and the casting 


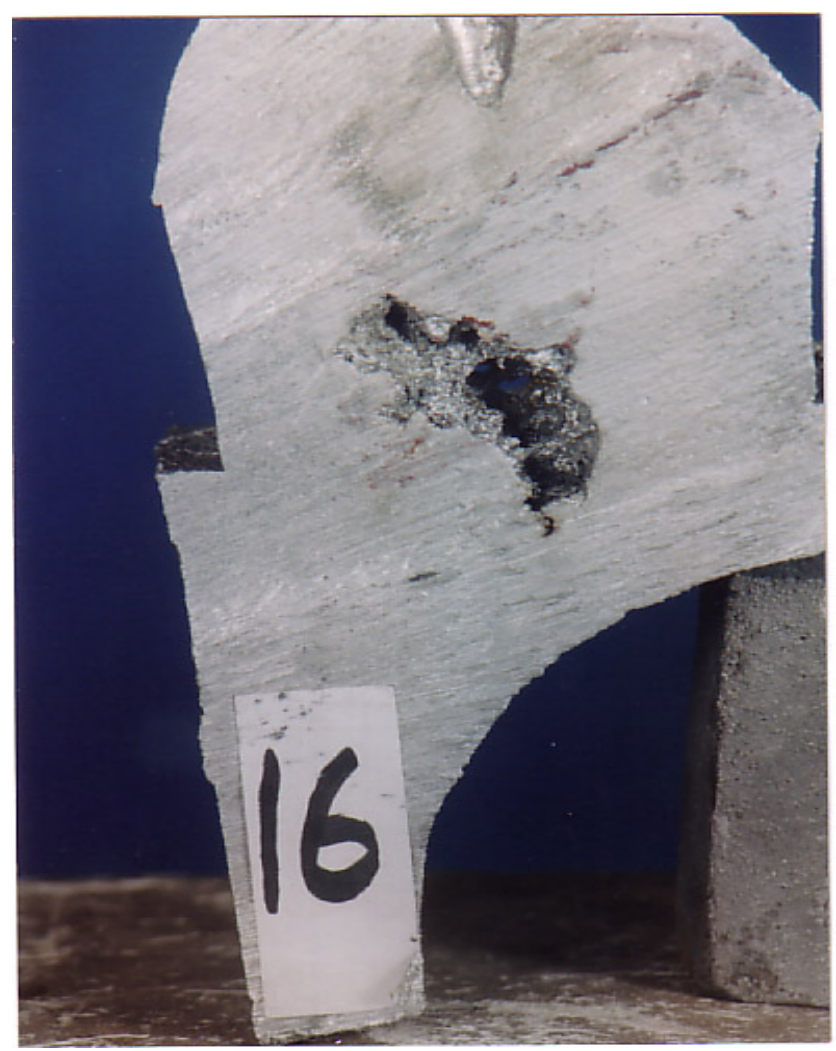

Fig.15 The photography of the small "L" with spherical riser and the pouring gate beside the casting

The calculation of the $\% \mathrm{C}$ for the risers used with the $\mathrm{L}$ section with small size showed greater value for the spherical riser than the elliptical riser and it was less than the values previously have been published.

Fig (16) shows that the \%C for elliptical riser is $5.5 \%$ and for the spherical riser it is $8.4 \%$. This is due to spherical riser is smaller in volume than the elliptical riser. 


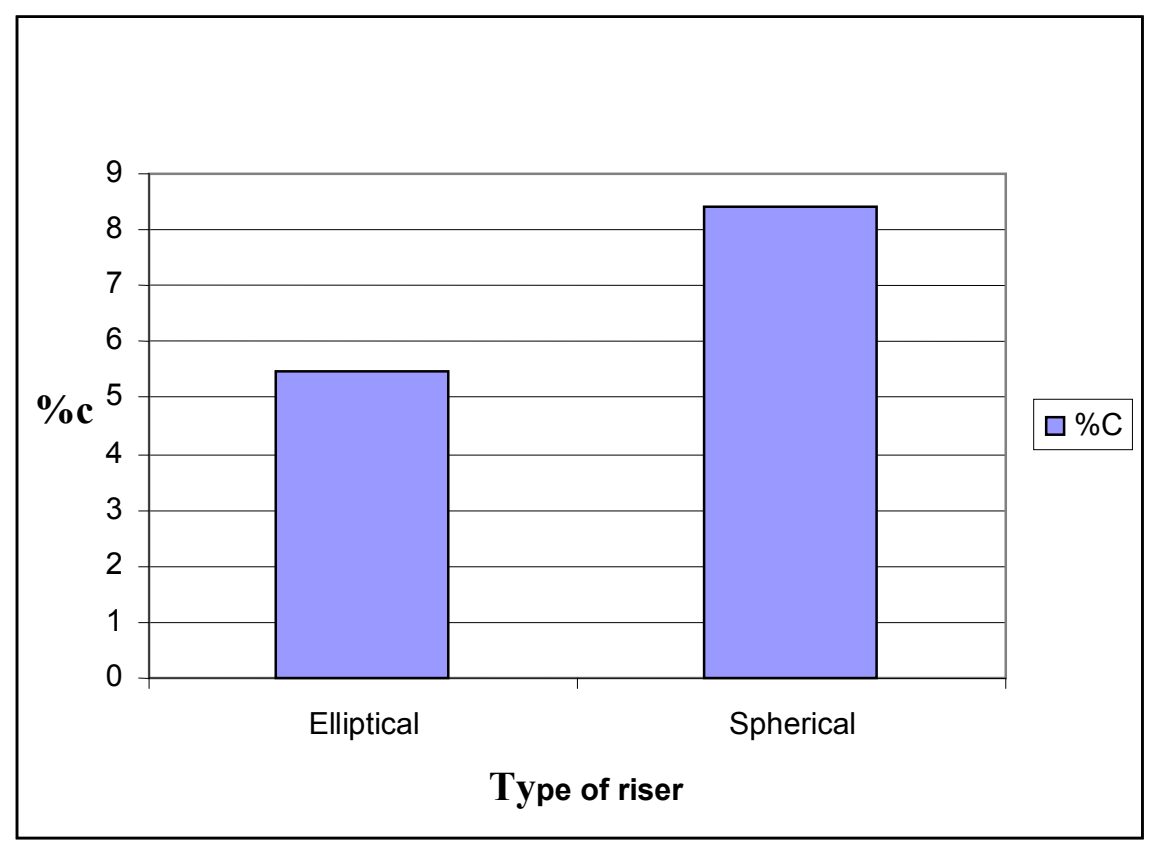

Fig. 16 The $\% C$ for elliptical and spherical risers used with the small $L$ section

\section{CONCLUSIONS}

- The riser design showed a great effect on both the quality and the casting economics of $\mathrm{Al}-10.7 \%$ Si alloy.

- The positions of the riser and the pouring gate influence significantly the quality of Al- Si castings.

- The surface area of the spherical riser is less than the elliptical riser leads to keep the metal inside the spherical riser in liquid state longer time and to improve the feeding process.

- The ratio of the riser volume to the casting volume of the spherical riser is less than of the elliptical riser and so it is more economically.

- The ratio of the riser modulus to the casting modulus for spherical riser is less than for the elliptical riser

- Blind risers are useful to maintain atmospheric pressure within the molten metal in the blind riser.

- William's core acts as a hot spot and atmospheric pressure in order to push the liquid metal from the riser into the casting.

- Adding the glass water as binder for sand mixture in the case of using spherical riser led to form shrinkage cavity shifted from the junction area due to its high thermal diffusivity.

- It is recommended to use spherical riser as it has lower surface area more economic but using a binder with lower thermal diffusivity.

- The casting of "L" section with large size when elliptical riser is used showed a sound casting when the pouring gate was placed beside the riser. 
- The spherical riser is recommended for the casting of "L"section with small size for the alloy (Al-10.7\% Si). Which save the metal by $40 \%$.

- The proportion of feed metal which meets the modulus requirements $(\% \mathrm{C})$ showed larger values for the elliptical risers than the spherical risers.

\section{REFERENCES}

1-William.F.Smith" Structure and properties of engineering alloys", 1995 Mc Grew- Hill, inc.

2- Lee A. Plutshack, Anthony $L$ and el, "Aluminum and Aluminum Alloys 1998 J.R Davis.

3- M. Taya and R.J. Arsenault, Metal Matrix Composites: Thermo mechanical Behavior (New York: Pergamon Press, 1989), p. 157.

4- JE. Gruzelski and BM. Closset, "The Treatment of Liquid Al-Si Alloys" (Des Plaines,

IL: AFS, 1990), pp. 13-15. 48. F. Dimayuga, Intl. Conf. of Molten Metal

5- Sumanth Shankar,Makhlouf Makhlouf ," Evolution of the Eutectic Microstructure During Solidification of Hypoeutectic Aluminum-Silicon Alloys", 2003, WPI, Advanced Casting Research Center - Research Programs.htm

6- John T Berry, The Effect of Applied Pressure During Feeding On The Fatigue Properties Of Critical Cast Aluminum Alloy Components, final report on CMC project June 2003, Mississippi State University

7- J. Campell, “Casting” 1991, Butterworth - Heinemann. Oxford, England

8- J.U. Ejiofor and R.G. Reddy, "Developments in the Processing and Properties of Particulate Al-Si Composites, JOM, 49, 1997, pp31-37

9- G.A.Edwards et al, Microporosity formation in Al-Si - Cu -mg casting alloys,AFStrans, vol.105,1997

10- T.T. El-Midany and M.A.Mansour, "Founder and Welding" Text book, Mansoura University press 1990 ,pp46-49

11- B.Kumar,"Manufacturing Technology", 1997, pp185-188, Khanna Publishers, Delhi

12- E.Paul DeGarmo, J Temple Black et al, "Materials and Processes in Manufacturing" $7^{\text {th }}$ edition, 1988 Macmillan publishing company, pp333-339.

13- John R. Brown," The Foseco Fountryman's Handbook, 1994, $10^{\text {th }}$ edition Butterworth - Heinemann, Pp287-312. 